\title{
Produção de bio-hidrogênio e metano por meio da codigestão de manipueira e dejetos suínos
}

\section{Biohydrogen and methane production by co-digestion of cassava and swine wastewater}

Data de entrada: $12 / 7 / 2016$

Data de aprovação: 06/11/2017

Eric Avilino Batista/ Norma Candida dos Santos Amorim/Luíza Rijo Valoura/ Williane Vieira Macêdo/ Eduardo Lucena Cavalcante de Amorim*

DOI: 10.4322/dae.2018.031

\section{Resumo}

O emprego da digestão anaeróbia no tratamento de resíduos agroindustriais possibilita a produção de gases de alto valor energético. Este trabalho avaliou a produção de hidrogênio em reator anaeróbio de leito fluidificado sequenciado por um reator anaeróbio de leito fixo alimentados com efluentes de suinocultura e manipueira, resíduo gerado a partir do processamento da mandioca. Os rendimentos de produção de hidrogênio no primeiro reator (reator acidogênico) encontrados nas Fases 1 (S25A50M25), 2 (S50A25M25), 3 (S75A10M15) e 4 (S85A0M15) foram respectivamente 1,13 (28,14\%), 0,57 (14,34\%), 0,63 (15,70\%) e 0,14 (3,61\%) $\mathrm{mol} \mathrm{H}_{2} / \mathrm{mol}_{\text {carboidrato. No }}$ reator metanogênico, as maiores produções de metano foram obtidas no tempo de detenção hidráulica (TDH) de 24 horas com valores na ordem de 12,11 $\pm 3,49 \mathrm{mLCH}_{4} / \mathrm{L}$.h, fase em que o afluente continha maior carga de matéria orgânica disponível. O maior rendimento foi obtido no TDH para 12 horas na ordem de $1,90 \mathrm{~mL} \mathrm{CH}_{4} / \mathrm{g}$ DQO . Palavras-chave: Produção de hidrogênio. Produção de Metano. Suinocultura. Manipueira.

\section{Abstract}

The use of anaerobic digestion in the treatment of agroindustrial waste enables the production of high energy gases. This work evaluated the hydrogen production in a fluidized bed anaerobic reactor sequenced by a fixed bed anaerobic reactor fed with swine effluent and cassava wastewater. The hydrogen yield (HY) in the first reactor (acidogenic reactor) found in Phases 1 (S25A50M25), 2 (S50A25M25), 3 (S75A10M15) and 4 (S85AOM15) were respectively 1.13 (28.14\%), 0.57 (14.34\%), 0.63 (15.70\%), and 0.14 (3.61\%) molH2/molcarbohydrate. In the methanogenic reactor, the highest methane production was obtained in the 24-hour hydraulic detention time (TDH) with values of $12.11 \pm 3.49 \mathrm{mLCH} 4 / \mathrm{Lh}$, where the inffluent contained the highest organic matter available. Furthermore, the highest yield (1.90 $\mathrm{mLCH} 4$ /gCOD) was obtained in TDH of 12 hours. Keywords: Hydrogen production. Methane production. Swine wastewater. Cassava wastewater.

Eric Avilino Batista - Graduado em Engenharia Ambiental e Sanitária pela Universidade Federal de Alagoas. Mestre em Recursos Hídricos e Saneamento pela Universidade Federal de Alagoas. Docente em instituições de nível superior.

Norma Candida dos Santos Amorim - Graduada em Engenharia de Agrimensura pela Universidade Federal de Alagoas. Mestre em Recursos Hídricos e Saneamento pela Universidade Federal de Alagoas. Doutoranda em Engenharia Civil (CTG/UFPE) na área de Tecnologia Ambiental e Recursos Hídricos. Professora Efetiva do Instituto Federal de Alagoas (Ifal).

Luíza Rijo Valoura - Graduanda do curso de Engenharia Civil na Universidade Federal de Alagoas.

Williane Vieira Macêdo - Graduada em Engenharia Ambiental e Sanitarista pela Universidade Federal de Alagoas. Mestranda em Engenharia Hidráulica e Saneamento pela Universidade de São Paulo (EESC/USP).

Eduardo Lucena Cavalcante de Amorim - Graduado em Engenharia Civil pela Universidade Federal de Alagoas. Mestre em Engenharia Hidráulica e Saneamento pela Escola de Engenharia de São Carlos (EESC) da Universidade de São Paulo. Doutor em Engenharia Hidráulica e Saneamento pela Universidade de São Paulo. Professor-adjunto do curso de Engenharia Ambiental e Sanitária e pesquisador do Centro de Tecnologia da Universidade Federal de Alagoas (UFAL).

"Endereço para correspondência: Rua Dr. Antonio Cansanção, 760, apto 401, Maceió-Alagoas. E-mail: eduardo.lucenaactec.ufal.br 


\section{INTRODUÇÃO}

Os processos de digestão anaeróbia de resíduos sólidos e líquidos permitem a produção de energia ao mesmo tempo em que promovem o controle ambiental por meio da redução e do tratamento de resíduos. A produção de biometano e bio-hidrogênio a partir da biomassa tem atraído muita atenção devido a problemas ambientais atuais, particularmente relacionados com o aquecimento global (DEMIREL et al, 2010). Para que a produção de energia possa ser favorável a partir da digestão de biomassa, essa biomassa deve ser encontrada no ambiente em abundância e deve ser prontamente degradável. No geral, resíduos agroindustriais atendem a esses requisitos (GUO et al, 2010). Dentre os resíduos agroindustriais, os de origem animal são considerados um dos mais poluentes, devido ao seu conteúdo elevado de matéria orgânica, nitrogênio e fósforo. $O$ adubo (fezes e urina) gerado por animais criados em confinamento (aviários, suínos, bovinos) pode causar degradação do solo, da água e da qualidade do ar (HUBBARD AND LOWRANCE, 1998).

A suinocultura tem relevância econômica e social no complexo agropecuário brasileiro, pois possibilita a produção de alimentos, geração de emprego e multiplicação de renda familiar. Esta pode ser considerada uma produção vantajosa quando comparada à criação de outras espécies de médio e grande porte, pois produz grandes quantidades de carne em intervalo de tempo menor e em espaço físico reduzido. Nos últimos 15 anos, o Brasil aumentou em mais de $600 \%$ as exportações e em $40 \%$ a produção de carne suína. 0 país está presente, hoje, em 69 mercados, e classifica-se em quarto lugar no ranking mundial de países produtores e exportadores. Em exportação, está atrás dos EUA, da União Europeia (27 países) e do Canadá. Em produção, vem depois da China, da União Europeia e dos Estados Unidos (ABIPECES, 2014). Além da atividade da suinocultura, destaca-se, principalmente no Nordeste brasileiro, a cultura da mandioca. A mandioca é um produto tipicamente brasileiro e caracteriza-se por ser tolerante às condições de seca e baixa fertilidade do solo. 0 Brasil é um dos maiores produtores mundiais de mandioca, cujo processamento para a produção de farinha e fécula dá origem a cerca de $7 \mathrm{~m}^{3}$ de água residuária por $\mathrm{kg}$ de raiz de mandioca processada. A água residuária do processamento da mandioca, a manipueira, é rica em carboidratos e tem alta demanda química de oxigênio (DQO) e demanda bioquímica de oxigênio (DBO), além de elevado teor de matéria orgânica (CAPPELLETTI, 2011). Apesar do seu potencial poluidor, as características da manipueira a tornam atrativa para a produção de hidrogênio.

Recentemente, a codigestão de diferentes resíduos orgânicos tem chamado atenção. Dentre as vantagens da cofermentação anaeróbica estão: melhores condições de $\mathrm{pH}$ e um melhor equilíbrio entre carbono e nitrogênio (WANG et al, 2013), a possibilidade do tratamento simultâneo de mais do que um tipo de águas residuais, a diluição de compostos tóxicos ou inibitórios, o aumento da produção de hidrogênio e o ajuste da relação entre carboidrato/proteína (GIOANNIS et al, 2013).

Wang et al (2013) avaliaram a codigestão da manipueira em reatores em batelada com quatro tipos de substratos suporte diferentes: lodo do tratamento de manipueira, lodo de sunicultura, lodo de bovinos em confinamento e lodo proveniente de um sistema de tratamento por lodos ativados. Os autores observaram um rendimento $46 \%$ maior da manipueira com lodo do tratamento de manipueira em relação à manipueira. Hernandez et al (2014) estudaram, por sua vez, o comportamento da codigestão da mucilagem do café com estrume de suínos. Os autores obtiveram um percentual máximo de $39 \%$ de hidrogênio no biogás. Marrone et al (2015) avaliaram a codigestão do efluente de criadouros de búfalo, soro de queijo e glicerol cru, a fim de avaliar a melhor composição para produção de hidrogênio, e concluíram que a produção de 
hidrogênio foi melhor quando o soro de queijo foi predominante na composição do substrato.

Rosa et al (2014) avaliaram o efeito da inóculo e do tempo de detenção hidráulica (TDH) na produção de hidrogênio em reator anaeróbio de leito fluidificado a partir de uma mistura de manipueira com glicose. Os autores obtiveram melhores rendimentos da produção de hidrogênio quando aplicaram o TDH de 6 horas.

Devido à fermentação poder usar substratos complexos, como resíduos de culturas agroindustriais, há várias oportunidades para desenvolver digestão anaeróbia de dois ou mais substratos com características complementares, tais como: fontes de carbono e nitrogênio, demanda química de oxigênio (DQO), pH, alcalinidade e micro-organismos. Os resíduos de suínos têm uma alta concentração de proteína e lipídios e têm sido amplamente utilizados na digestão anaeróbia como substrato suporte durante o tratamento de outros resíduos (HERNANDEZ et al 2014). Já a manipueira possui grande teor de carboidratos. Assim, a utilização de ambos os resíduos poderia ser viável, caso sua produção seja em regiões geográficas semelhantes. Nesse cenário, o presente trabalho utilizou o resíduo proveniente da atividade da suinocultura associada à manipueira para a produção de hidrogênio e metano em reatores anaeróbios de leito fluidificado e fixo, avaliando a produção desses gases por meio dos metabólitos solúveis produzidos e indicando a rota fermentativa em que o processo se conduziu.

\section{METODOLOGIA}

\subsection{Configuração e condições operacionais dos Reatores Anaeróbios}

O experimento consistiu na utilização de dois reatores, sendo um anaeróbio de leito fluidificado para a fase acidogênica (RALF) e um anaeróbio de leito fixo (RFixo) para a fase metanogênica. 0 esquema de operação dos reatores está disposto na Figura 1.

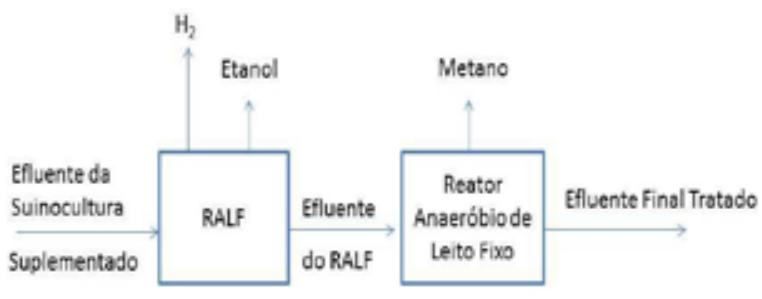

Figura 1: Esquema de operação dos reatores.

O reator anaeróbio de leito fluidificado foi construído em acrílica transparente como material base, possui espessura de $05 \mathrm{~mm}$, altura de aproximadamente 90 cm e 5,3 cm de diâmetro interno. $O$ reator anaeróbio de leito fixo foi construído utilizando tubos de acrílico com diâmetro interno de $80 \mathrm{~mm}$, diâmetro externo de $88 \mathrm{~mm}$ e $750 \mathrm{~mm}$ de comprimento. Os reatores foram operados sob a temperatura ambiente que correspondeu a uma variação de $26^{\circ} \mathrm{C}$ até $34^{\circ} \mathrm{C}$. O sistema de alimentação se deu de forma contínua em que, durante todas as fases operacionais, o efluente do reator acidogênico alimentava o reator metanogênico. Como o tempo de detenção hidráulica (TDH) do reator acidogênico era muito inferior ao TDH do reator metanogênico, o efluente era acumulado temporariamente em um recipiente que alimentava o reator metanogênico. Dessa forma, pequenas variações da DQOO de entrada do reator metanogênico em comparação à DQO de saída do acidogênico podem se dar pela equalização do efluente que ocorreu no recipiente de equalização.

A fim de identificar as eficiências de remoção de matéria orgânica e de produção biogás, diferentes proporções que compunham a mistura 'efluente de suinocultura + manipueira' foram estudadas e estão dispostas na Tabela 01. O tempo de detenção hidráulica (TDH) de cada reator também está estabelecido da tabela supracitada. A redução do TDH no reator metanogênico objetivou investigar se determinado volume de efluente poderia ser tratado em um menor intervalor de tempo, e consequentemente menor tempo de reação para a as arqueas metanogênicas, sem a alteração das composição do biogás. 
Tabela 1: Composição do substrato (\%) e TDH dos reatores.

\begin{tabular}{|c|c|c|c|c|c|c|}
\hline \multirow{2}{*}{ Fase } & Nomenclatura & \multicolumn{2}{|c|}{ Composição do substrato (\%) } & \multicolumn{2}{c|}{ TDH (horas) } \\
\cline { 3 - 7 } & & $\begin{array}{c}\text { Resíduo de } \\
\text { suínos }\end{array}$ & Água & Manipueira & RALF & RFixo \\
\hline 1 & S25A50M25 & 25 & 50 & 25 & 4 & 24 \\
\hline 2 & S50A25M25 & 50 & 25 & 25 & 4 & 12 \\
\hline 3 & S75A10M15 & 75 & 10 & 15 & 4 & 12 \\
\hline 4 & S85A0M15 & 85 & 0 & 15 & 4 & 12 \\
\hline
\end{tabular}

\subsection{Partida dos Reatores}

No RALF, a adaptação de micro-organismos (biomassa) foi feita dentro do próprio reator, contendo as partículas de argila expandida (diâmetro de 2,8-3,35 mm) como meio suporte para a adesão microbiana e formação do biofilme, a fim de imobilizar a biomassa (Amorim et al 2009). O inóculo utilizado foi lodo proveniente do resíduo de suinocultura. Inicialmente, foi utilizado um inóculo diluído em água passando por um período de adaptação durante 48 horas a fim de que microrganismos previamente selecionados através do método de pré-tratamento térmico conforme MAINTINGUER et al. (2008) aderissem ao material. No reator anaeróbio de leito fixo foi utilizado o efluente do reator anaeróbio de leito fluidificado para inoculação. A adaptação da população microbiana foi feita no próprio reator, utilizando-se a concha de sururu para a aderência microbiana. Não foram submetidos tratamentos térmicos, sendo o reator exposto à temperatura ambiente. As conchas de sururu foram escolhidas como material suporte por serem um resíduo abundante na região de estudo e por sua composição química que confere álcali a partir da liberação de bicarbonato ao sistema ao passo que vai sendo lentamente consumida no sistema.

\subsection{Medição de hidrogênio e metano e métodos analíticos}

Foi utilizado um medidor MilliGas-counter do fabricante Ritter modelo MGC-1 V3 1 AMMA para quantificar a produção volumétrica de hidrogê- nio e metano. $\mathrm{O}$ acompanhamento do $\mathrm{pH}$ e da demanda química de oxigênio (DOO) foi realizado conforme APHA (1998). A concentração de carboidratos foi medida a partir da metodologia desenvolvida por Dubois et al (1956), e a concentração dos ácidos orgânicos e álcoois foi realizada por meio de cromatografia gasosa segundo a metodologia de Maintinguer et al (2008).

\section{RESULTADOS E DISCUSSÃO}

\subsection{Comportamento do Reator Anaeróbio de Leito Fluidificado - Produção de Hidrogênio}

A Figura 2 apresenta a variação do $\mathrm{pH}$ ao longo do experimento. Não houve adição de qualquer substância química para o controle do $\mathrm{pH}$ ao longo do experimento. $\mathrm{O} \mathrm{pH}$ variou entre 4,135,91 para o afluente e 4,33-7,37 para o efluente, apresentando-se na faixa satisfatória para a produção de hidrogênio segundo a literatura (LAMAISON, 2009; CAPPELLETTI et al, 2011). $\mathrm{Na}$ fase 4 foi observado um aumento do $\mathrm{pH}$ que pode ser justificado pela concentração de resíduo da suinocultura ser predominante em relação à manipueira ( $85 \%$ e $15 \%$, respectivamente) durante esta fase, fazendo com que o $\mathrm{pH}$ aumente e resultando em menor rendimento da produção de hidrogênio $\left(0,14 \mathrm{~mol} \mathrm{H}_{2} / \mathrm{mol}\right.$ glicose). Segundo a literatura, a faixa de $\mathrm{pH}$ do sistema em questão encontra-se adequada. Chen et al. (2002) estima que para uma produção de hidrogênio ideal o $\mathrm{pH}$ tem que apresentar uma faixa entre 5,5 e 6. Cardoso (2013) encontrou uma produção volumétrica de hidrogênio máxima no pH 5, 1 (0,65 $\mathrm{L} / \mathrm{h} / \mathrm{L})$ seguido pelos $\mathrm{pHs} 4,7(0,42 \mathrm{~L} / \mathrm{h} / \mathrm{L})$ e 5,0 
(0,46 L/h/L), a partir de um RALF utilizando solução de manipueira como substrato. Já para o rendimento de hidrogênio, o autor encontrou um valor máximo no $\mathrm{pH}$ de $4,9\left(3,5 \mathrm{~mol} \mathrm{H}_{2} / \mathrm{mol}\right.$ de glicose) seguido pelos $\mathrm{pHs} 5,1\left(3,30 \mathrm{~mol} \mathrm{H}_{2} / \mathrm{mol}\right.$ de glicose) e 4,5 (3,20 $\mathrm{mol} \mathrm{H}_{2} / \mathrm{mol}$ de glicose).

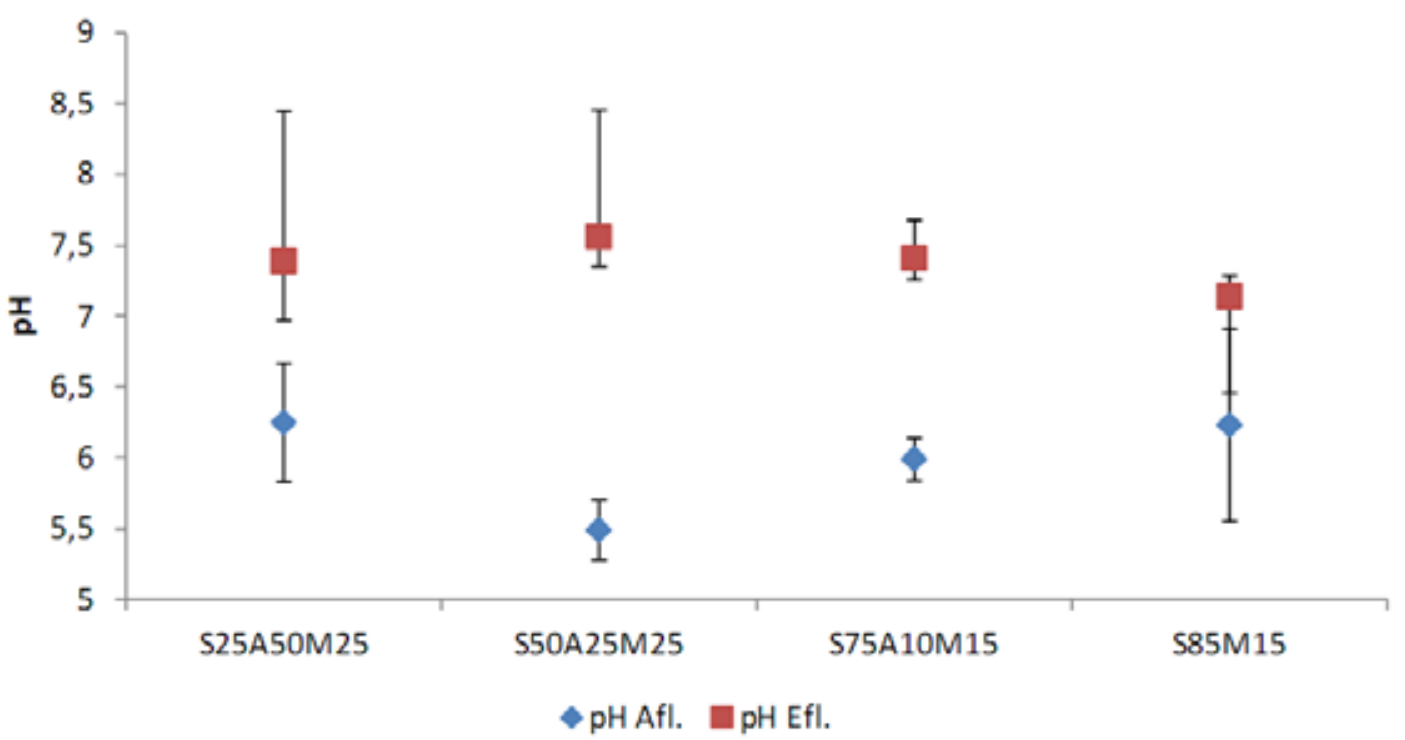

Figura 2: Variação do pH afluente e efluente em cada fase experimental

A tabela 2 apresenta os valores médios dos carboidratos afluente e efluente e também a eficiência de remoção.

Tabela 2: Carboidratos totais médio afluente e efluente; Eficiência de conversão.

\begin{tabular}{|c|c|c|c|c|}
\hline Fases & $\begin{array}{c}\text { Concentração } \\
\text { do substrato }\end{array}$ & $\begin{array}{c}\text { Afluente } \\
\text { (mg. } \mathbf{L}^{-1} \text { ) }\end{array}$ & $\begin{array}{c}\text { Efluente } \\
\text { (mg. } \mathbf{L}^{-1} \text { ) }\end{array}$ & Eficiência (\%) \\
\hline 1 & S25A50M25 & 6411,24 & 3444,63 & 46 \\
\hline 2 & S50A25M25 & 6419,58 & 3967,25 & 38 \\
\hline 3 & S75A10M15 & 3866,77 & 1838,61 & 52 \\
\hline 4 & S85M15 & 3870,11 & 1008,54 & 74 \\
\hline
\end{tabular}

A variação da concentração afluente de carboidratos pode ser atribuída ao percentual de manipueira na solução, uma vez que a manipueira possui maior quantidade de carboidratos do que o resíduo de suinocultura. Observa-se que maior eficiência da conversão de carboidratos foi obtida na fase 4 (74\%), a qual possuía menor percentual de manipueira e menor diluição. Nas fase 1 e 2, a taxa de conversão de carboidratos pode ter sido prejudicada pela sobrecarga do sistema com o maior percentual de manipueira aplicado. $\mathrm{Na}$ fase 3 , com a redução do volume de manipueira aplicado, observou-se um aumento na eficiência de conversão chegando a seus valores máximos na fase 4 . Os valores encontrados neste trabalho corroboram a literatura. Zhang et al (2007), Barros et al (2010) e Reis (2010) obtiveram conversões variando de $70,50 \%$ a $96,3 \%$ utilizando como substrato águas de estudo contendo glicose como substrato, matéria orgânica facilmente degradável.

A variação da eficiência de remoção de DQ foi constante ao longo de todas as fases experimentais. A Tabela 3 apresenta o comportamento da DQO em cada fase operacional. A eficiência de remoção de DQQO média foi de $29 \%$. 
Tabela 3: DQQOs média afluente e efluente; Eficiência de conversão.

\begin{tabular}{|c|c|c|c|c|}
\hline Fases & $\begin{array}{c}\text { Concentração } \\
\text { do substrato }\end{array}$ & $\begin{array}{c}\text { Afluente } \\
\text { (mg..-1) }\end{array}$ & $\begin{array}{c}\text { Efluente } \\
\left(\mathbf{m g . L}^{-\mathbf{1}} \mathbf{)}\right.\end{array}$ & Eficiência (\%) \\
\hline 1 & S25A50M25 & 6885,97 & 4978,55 & 28 \\
\hline 2 & S50A25M25 & 6946,44 & 4947,95 & 29 \\
\hline 3 & S75A10M15 & 4276,72 & 3064,69 & 28 \\
\hline 4 & S85M15 & 4300,91 & 3026,55 & 30 \\
\hline
\end{tabular}

Atrelada ao processo de remoção de carboidratos está a constante produção de ácidos orgânicos de cadeia curta que irão conferir DQO ao sistema, o que explica eficiências similares mesmo quando houve diferentes proporções de remoção de carboidratos. Ainda, os valores de remoção obtidos neste trabalho corroboram a literatura, uma vez que, segundo von Sperling (2014), em sistemas acidogênicos espera-se uma eficiência na remoção de DQO de $20 \%$ a $30 \%$.

A produção volumétrica de hidrogênio está detalhada na figura 3. As fases 2 e 3 foram os momentos onde o maior volume de gás foi produzido, atingindo um pico de $0,536 \mathrm{~L} / \mathrm{h} / \mathrm{L}$ na terceira fase e um valor mínimo de $0,17 \mathrm{~L} / \mathrm{h} / \mathrm{L}$ na primeira fase.

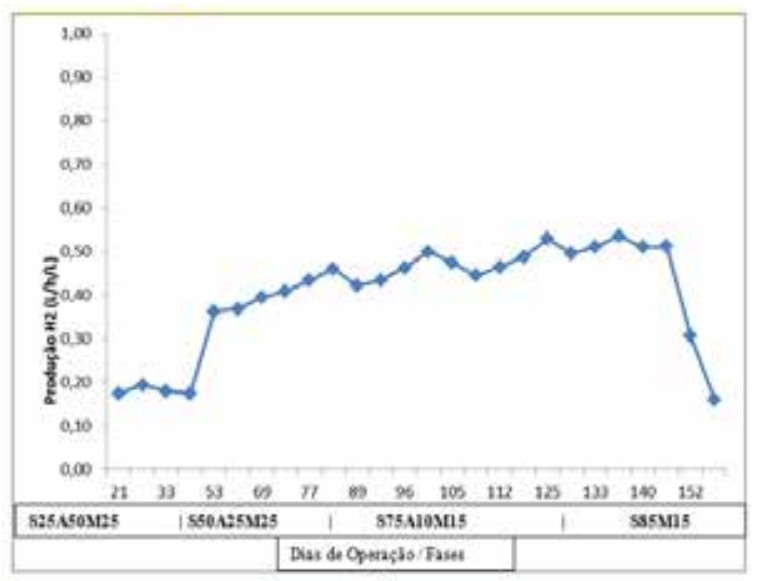

Figura 3: Comportamento da Produção Volumétrica de Hidrogênio ao longo das fases.

Diferentes rotas fermentativas de produção ácidos graxos de cadeira curta podem ocorrer no processo da biodigestão anaeróbia. Objetivando a produção de hidrogênio, a principal rota é a do ácido acético seguida pela do ácido butírico (Equação 1 e 2, respectivamente) devido ao rendimento teórico que pode ser obtido. A rota do ácido propiônico, por sua vez, deve ser evitada já que moles de hidrogênio são consumidos na reação (Equação 3) (REIS, 2010).

$$
\mathrm{C}_{6} \mathrm{H}_{12} \mathrm{O}_{6}+2 \mathrm{H}_{2} \mathrm{O} \rightarrow 2 \mathrm{CH}_{3} \mathrm{COOH}+2 \mathrm{CO}_{2}+4 \mathrm{H}_{2} \quad \Delta \mathrm{G}=-215,69 \mathrm{~kJ} / \mathrm{mol} \quad \text { Equação. } 1
$$

$$
\mathrm{C}_{6} \mathrm{H}_{12} \mathrm{O}_{6}+2 \mathrm{H}_{2} \mathrm{O} \rightarrow \mathrm{CH}_{3} \mathrm{CH}_{2} \mathrm{CH}_{2} \mathrm{COOH}+2 \mathrm{CO}_{2}+2 \mathrm{H}_{2} \quad \Delta \mathrm{G}=-257,1 \mathrm{~kJ} / \mathrm{mol} \quad \text { Equação. } 2
$$

$$
\mathrm{C}_{6} \mathrm{H}_{12} \mathrm{O}_{6}+2 \mathrm{H}_{2} \quad \rightarrow \quad 2 \mathrm{CH}_{3} \mathrm{CH}_{2} \mathrm{COOH}+2 \mathrm{H}_{2} \mathrm{O} \quad \Delta \mathrm{G}=-358 \mathrm{~kJ} / \mathrm{mol} \quad \text { Equação. } 3
$$

Na tabela 4 está detalhada a produção volumétrica média (HPR), o rendimento de hidrogênio (HY) ao longo das fases operacionais e o rendimento da produção de hidrogênio, considerando a produção máxima aquela obtida por meio da rota do ácido acético, que estabelece a relação de $1 \mathrm{~mol}$ de glicose : 4 moles de hidrogênio. A produção volumétrica de hidrogênio apresentou um comportamento crescente no momento em que a concentração da manipueira foi diminuída, ao passo que o rendimento de produção de hidrogênio foi diminuindo ao longo das fases. 
Tabela 4: Produção Volumétrica de Hidrogênio média e rendimento ao longo das fases.

\begin{tabular}{|c|c|c|c|c|}
\hline Fases & $\begin{array}{c}\text { Concentração } \\
\text { do substrato }\end{array}$ & $\begin{array}{c}\text { HPR } \\
\text { (L/h/L) }\end{array}$ & $\begin{array}{c}\text { HY } \\
\text { (mol H2/ } \\
\text { mol glicose) }\end{array}$ & $\begin{array}{c}\text { (\%) do } \\
\text { rendimento }\end{array}$ \\
\hline 1 & S25A50M25 & 0,18 & 1,13 & 28 \\
\hline 2 & S50A25M25 & 0,24 & 0,57 & 14 \\
\hline 3 & S75A10M15 & 0,43 & 0,63 & 16 \\
\hline 4 & S85M15 & 0,45 & 0,14 & 4 \\
\hline
\end{tabular}

Ao utilizar apenas manipueira como substrato, Amorim et al (2014) obtiveram uma eficiência máxima de $48 \%$ na produção de hidrogênio. Já Santos (2014) obteve uma eficiência máxima de $43 \%$ utilizando resíduo de suíno suplementado com sacarose. A queda do rendimento de hidrogênio na fase 4 sugere a predominância outras rotas fermentativas que não favorecem a produção de hidrogênio, o que pode ser evidenciado a partir da Figura 4, que mostra maior produção de ácido propiônico na fase 4 .

\subsection{Composição dos produtos solúveis e balanço de carbono}

A Figura 4 apresenta a variação da concentração de metabólitos solúveis produzidos durante a operação do RALF. Foi observada a presença dos seguintes metabólitos: ácido acético, ácido butírico, ácido propiônico e etanol. Os ácidos acético e butírico foram os únicos metabólitos observados em todas as fases de operação do reator. As concentrações variaram entre 1,26-5 mM para o ácido acético, 0,55-2,7 mM para o ácido butírico, 0-1,33 mM para o ácido propiônico e 0-1,75 mM para o etanol.

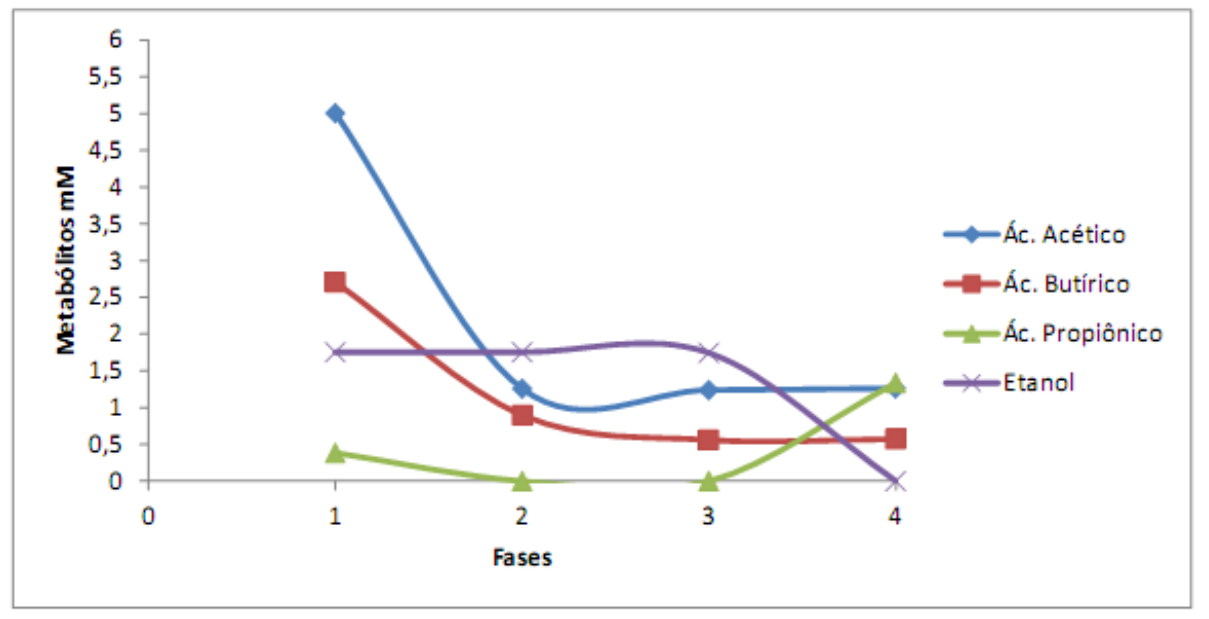

Figura 4: Metabólitos produzidos durante a operação do RALF das fases de operação.

Segundo Reis (2010), quanto maior a relação Ácido Acético/Ácido Butírico (HAc/HBu), maior será a produção de hidrogênio, tendo em vista que a rota de produção do ácido acético rende quatro moles de hidrogênio em vez de dois moles gerados pela rota butírica. As razões estão detalhadas na Tabela 5 .
Tabela 5: Proporção HAc/HBu em função das fases.

\begin{tabular}{|c|c|c|}
\hline Fase & Concentração do substrato & HAc/HBu \\
\hline 1 & S25A50M25 & 1,85 \\
\hline 2 & S50A25M25 & 1,40 \\
\hline 3 & S75A10M15 & 2,23 \\
\hline 4 & S85M15 & 2,21 \\
\hline
\end{tabular}


Na fase 1 houve presença de todas as rotas quantificadas, o que indica que houve produção de hidrogênio assim como também houve consumo. No entanto, a predominância dos ácidos acético $(5 \mathrm{mM})$ e butírico $(2,7 \mathrm{mM})$, e do etanol $(1,75 \mathrm{mM})$ sobre do ácido propiônico $(0,38 \mathrm{mM})$, justificam o melhor rendimento nessa fase $\left(1,13 \mathrm{~mol} \mathrm{H}_{2} / \mathrm{mol}\right.$ glicose).

$\mathrm{Na}$ fase 2 houve uma queda no rendimento da produção de hidrogênio $\left(0,57 \mathrm{~mol} \mathrm{H}_{2} / \mathrm{mol}\right.$ glicose). Esse fato pode ser justificado pela diminuição da concentração dos ácidos acético e butírico (1,25 e $0,89 \mathrm{mM}$, respectivamente) em relação à fase anterior. A produção de etanol manteve-se constante e não houve produção de ácido propiônico.
O rendimento de hidrogênio tem um leve aumento na fase 3 ( $0,63 \mathrm{~mol} \mathrm{H}_{2} / \mathrm{mol}$ glicose), que pode ser justificado por essa fase possuir maior relação $\mathrm{HAc/HBu}$ em relação à fase 2 (Tabela 5 ). $\mathrm{O}$ aumento da produção de ácido propiônico (1,33 mM) na fase 4 levou à diminuição do rendimento da produção de hidrogênio $\left(0,14 \mathrm{~mol} \mathrm{H}_{2} / \mathrm{mol}\right.$ glicose), indicando a relação direta entre a produção desse metabólito com o consumo de hidrogênio.

A presença do etanol em maiores concentrações nas três primeiras fases deste experimento pode indicar a possibilidade de produção de hidrogênio por meio da rota metabólica indicada da reação 4, que produz etanol e hidrogênio simultaneamente.

$\mathrm{C}_{6} \mathrm{H}_{12} \mathrm{O}_{6}+\mathrm{H}_{2} \mathrm{O} \rightarrow \mathrm{C}_{2} \mathrm{H}_{5} \mathrm{OH}+\mathrm{CH}_{3} \mathrm{COOH}+2 \mathrm{H}_{2}+2 \mathrm{CO}_{2} \quad \Delta \mathrm{G}=-201 \mathrm{~kJ} / \mathrm{mol} \quad$ Equação. 4

Li et al (2010) encontraram a menor produção metabólica de ácido acético $(1,48 \mathrm{mM})$ num $\mathrm{pH}$ de 5,0 e a maior produção $(9,97 \mathrm{mM})$ no $\mathrm{pH}$ de 5,9 . Os autores utilizaram a fermentação para a produção biológica de hidrogênio utilizando efluente da suinocultura suplementado com glicose. Também foram identificados os ácidos butírico e propiônico, bem como o etanol, mas a sua distribuição foi altamente dependente do $\mathrm{pH}$.

Os resultados encontrados para os metabólitos solúveis nos mostra que, neste estudo, as concentrações dos ácidos individualizados foram influenciadas pela variação da quantidade de resíduo suplementado ao longo das fases. Além disso, a diferença encontrada neste estudo e nos demais relatados demonstra a necessidade de controlar a manutenção das populações acidogênicas e prevenir a contaminação de outros organismos não produtores de hidrogênio, tais como as leveduras, no sistema que levaria a competição pelo substrato (AMORIM, 2012).

A Tabela 6 apresenta o balanço de carbono de cada metabólito e a DQO total a DQO efluente medida e a diferença entre a DQO teórica total e a efluente medida.

Tabela 6: Média das DQQOs teóricas dos metabólitos, DQQ da biomassa e DQQO efluente medida.

\begin{tabular}{|c|c|c|c|c|c|c|c|c|c|}
\hline Fase & $\begin{array}{c}\text { DQO } \\
\text { HAC } \\
(m g / L)\end{array}$ & $\begin{array}{c}\mathrm{DQO}_{\mathrm{t}} \\
\mathrm{HBu} \\
(\mathrm{mg} / \mathrm{L})\end{array}$ & $\begin{array}{c}\mathrm{DQO}_{\mathrm{t}} \\
\mathrm{HPr} \\
(\mathrm{mg} / \mathrm{L})\end{array}$ & $\begin{array}{l}\text { DQO } \\
\text { EtOH } \\
(\mathrm{mg} / \mathrm{L})\end{array}$ & $\begin{array}{l}\text { DQO } \\
\text { Glicose } \\
\text { (mg/L) }\end{array}$ & $\begin{array}{c}\text { DQO } \\
\text { Biomassa } \\
\text { (mg/L) }\end{array}$ & $\begin{array}{l}\text { DQO } \\
\text { Total } \\
\text { (mg/L) }\end{array}$ & $\begin{array}{l}\text { DQO }_{\mathrm{t}} \\
\text { Efluente } \\
\text { (mg/L) }\end{array}$ & $\begin{array}{c}\text { DQO } \\
\text { Total-Efluente } \\
\text { (mg/L) }\end{array}$ \\
\hline 1 & 320,33 & 433,22 & 43,03 & 168,35 & 3671,97 & 150,50 & 4787,4 & 4978,5 & 191,1 \\
\hline 2 & 80,34 & 143,43 & 0 & 168,39 & 4229,09 & 175,89 & 4797,14 & 4947,9 & 150,76 \\
\hline 3 & 79,30 & 89,42 & 0 & 167,43 & 1959,96 & 189,76 & 2485,87 & 3064,6 & 578,73 \\
\hline 4 & 80,70 & 91,30 & 149,82 & 0 & 1075,11 & 195,58 & 1592,51 & 3026,5 & 1433,99 \\
\hline
\end{tabular}


Os valores encontrados na diferença das DQOS teórica total e efluente medida foram elevados, principalmente nas fases 3 (S75A10M15) e 4 (S85M15). Possivelmente algum metabólito que existia nas soluções medidas não foi quantificado. $\mathrm{Na}$ fase $4 \mathrm{o}$ ácido propiônico prevaleceu, indicando que a diminuição da concentração de carboidratos da solução pouco favorece a produção de hidrogênio, uma vez que o metabólito consome hidrogênio em sua rota.

\subsection{Comportamento do Reator Anaeróbio de Leito Fixo - Produção de Metano}

O reator anaeróbio de leito fixo apresentou um percentual médio de remoção de DQQO de $26 \%$, e a remoção máxima foi atingida na quarta fase com eficiência média de $31 \%$, fase em que a maior concentração de carboidratos proveniente da manipueira aplicada ao reator acidogênico foi atingida. A Tabela 7 apresenta as médias afluente e efluente, assim como a remoção da DQO.
Tabela 7: DQQOs médias afluente e efluente e eficiência de remoção (RFixo).

\begin{tabular}{|c|c|c|c|c|}
\hline Fases & $\begin{array}{c}\text { Concentração } \\
\text { do substrato }\end{array}$ & $\begin{array}{c}\text { Afluente } \\
\text { (mg. }\end{array}$ & $\begin{array}{c}\text { Efluente } \\
\text { (mg.L-1) }\end{array}$ & Eficiência (\%) \\
\hline 1 & S25A50M25 & 4978,55 & 3536,26 & $29 \%$ \\
\hline 2 & S50A25M25 & 4947,95 & 3964,79 & $20 \%$ \\
\hline 3 & S75A10M15 & 3064,69 & 2372,07 & $23 \%$ \\
\hline 4 & S85M15 & 3026,55 & 2077,72 & $31 \%$ \\
\hline
\end{tabular}

Os resultados obtidos mostraram que os valores da DQQ afluente e efluente não tiveram variações bruscas, assim como os índices de eficiência de remoção. Buitron et al (2014) obtiveram uma eficiência de remoção em torno de 56\%, 65\% e $67 \%$ para DQQ afluente de 400, 1085 e 1636 mg/L, respectivamente. A remoção máxima de $\mathrm{DQO}$ foi observada quando o reator UASB foi operado em um TDH de 24 horas. $\mathrm{O}$ pH efluente do RFixo permaneceu próximo à neutralidade, o que indica que as bactérias acidogênicas foram inibidas e o ambiente metanogênico foi estabelecido com sucesso. Além disso, foi observada a eficiência do material suporte utilizado neste reator para conferir alcalinidade ao sistema, como previamente neste trabalho. Os valores de $\mathrm{pH}$ afluente e efluente estão dispostos na Figura 5 abaixo.

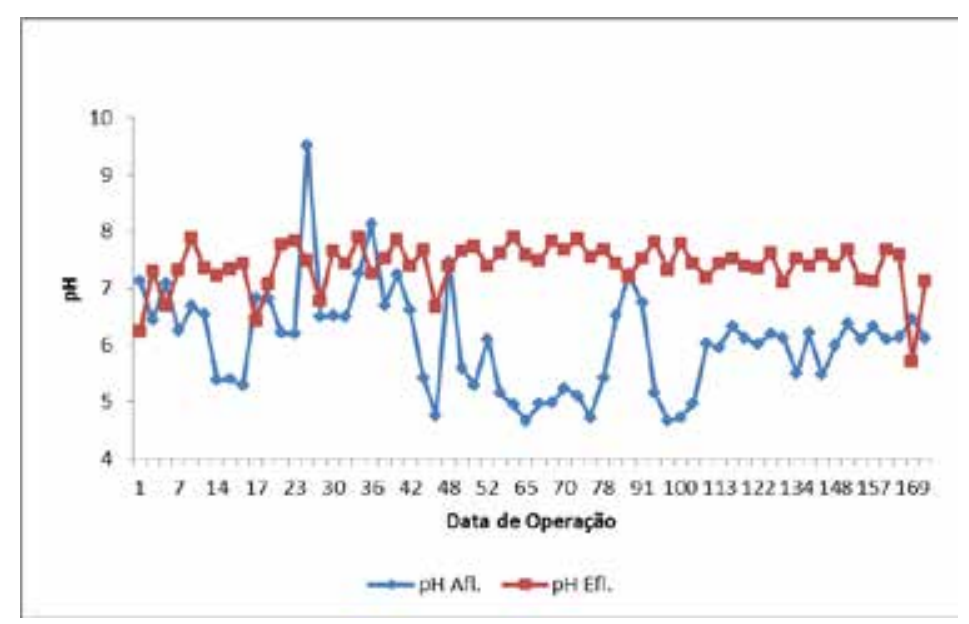

Figura 5: Comportamento temporal (dias) do $\mathrm{pH}$ (RFIXO). 
As maiores produções de metano foram obtidas no TDH de 24 horas com valores de 12,11 $\pm 3,49$ $\mathrm{ml} \mathrm{CH} /$ L.h. A redução do TDH para 12 horas resultou em uma menor produção de metano, 5,37 $\pm 3,48 \mathrm{ml} \mathrm{CH} /$ L.h. $O$ desempenho da produção do reator metanogênico em função do tempo de detenção hidráulica é mostrado nas Figuras 6 e 7. Houve significativa variação na quantidade de metano no biogás. Os maiores volumes encontrados foram da fase $1 \mathrm{com}$ TDH de 24 horas, fase em que o afluente do Rfixo encontrou maior carga de matéria orgânica disponível.

Resultado semelhante foi observado por Riaño et al. (2011), que estudaram a produção de metano a partir da codigestão do resíduo de suinocultura com água residuária da produção de vinho. Os autores observaram que a produção de metano aumentou $45 \%, 69 \%$ e $75 \%$ em relação ao obtido da digestão do resíduo de suinocultura sozinho quando $10 \%, 25 \%$ e $40 \%$ de água residuária da produção de vinho foi adicionada ao sistema, a qual também era a principal fonte de carboidratos. Além disso, os autores também obtiveram maior remoção de carga orgânica para $40 \%$ de água residuária da produção de vinho.

Buitron et al (2014) encontrou a produção máxima de metano $\left(11,7 \pm 0,7 \mathrm{ml} \mathrm{CH}_{4} /\right.$ L.h) e um máximo rendimento $\left(7,2 \pm 0,4 \mathrm{~mL} \mathrm{CH}_{4} / \mathrm{g}\right.$ DQQO) no TDH de 24 horas em reatores UASB alimentados com resíduos da fermentação de tequila. No entanto, resultados semelhantes foram obtidos com TRH $18 \mathrm{~h}$, valores na ordem de 12,2 \pm $1,2 \mathrm{ml} \mathrm{CH} 4 /$ L.h.

Colin et al (2007) produziu em um reator UASB alimentado com manipueira com carga orgânica de 11,8 g DQO/L.d um volume de biogás de 3,7 L/L.d com $69-81 \%$ em conteúdo de metano. O TDH aplicado foi de 9,5 horas.

\section{TDH 24h}

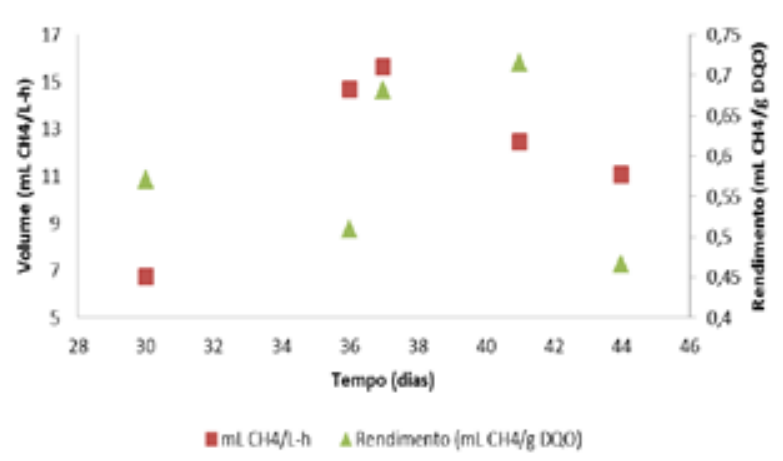

Figura 6: Volume de metano produzido, rendimento obtido num TDH de 24 horas.

\section{TDH $12 \mathrm{~h}$}

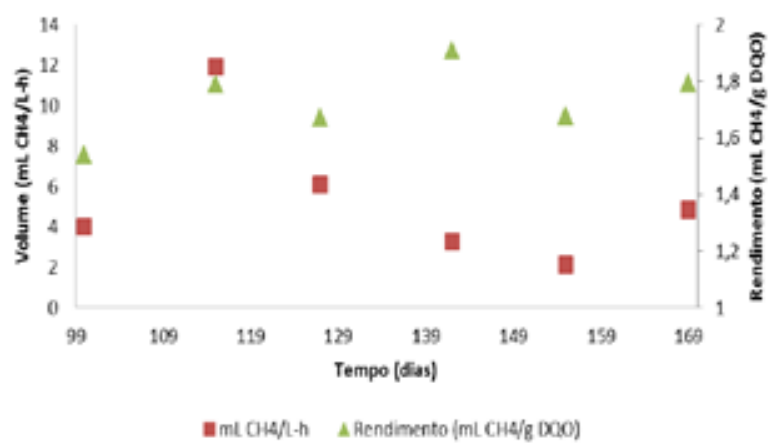

Figura 7: Volume de metano produzido, rendimento obtido num TDH de 12 horas.

\section{CONCLUSÕES}

Ao longo das fases, quando é diminuída a concentração de carboidratos a partir da proporção de mistura estabelecida para a codigestão, o rendimento da produção de hidrogênio tem seus valores diminuídos. A produção máxima de hidrogênio ocorreu na fase 1 , indicada pelo melhor rendimento de produção de hidrogênio e pela baixa concentração de ácido propiônico. Possivelmente outras rotas fermentativas desfavoráveis à geração de hidrogênio ocorreram, principalmente na fase 4 , onde houve maior diferença entre a DQO teórica e a DQO do efluente medida. Os parâmetros físico-químicos analisados no Reator Anaeróbio de Leito Fixo apresentaram condições compatíveis com a literatura. A casca de sururu estabilizou o $\mathrm{pH}$, mantendo-o próximo da neutralidade. Com isso, é mostrada a eficiência no efeito tampão, 
o que evita manifestação das bactérias acidogênicas. A remoção da DQO atingiu eficiências em torno de $26 \%$, devido à presença de matéria orgânica resistente ao primeiro tratamento. O TDH de 24 horas e a maior concentração de manipueira proporcionaram as maiores produções de metano. Dessa forma, conclui-se que o sistema foi favorecido pela adição da manipueira no processo de codigestão.

\section{REFERÊNCIAS}

ABIPECS. Em 15 anos, Brasil se tornou o $4^{\circ}$ maior produtor e exportador mundial de carne suína. Disponível em <http://www. abipecs.org.br/news/710/134/Em-15-anos-Brasil-se-tornou-o-4-maior-produtor-e-exportador-mundial-de-carne-suina. html>. Acesso em: 10 de fevereiro, 2014.

AMORIM, E. L. C. et al. (2009). Anaerobic fluidized bed reactor with expanded clay as support for hydrogen production through dark fermentation of glucose. International Journal of Hydrogen Energy, vol. 34 (2), 783-790.

AMORIM, N. C. S. Produção de hidrogênio a partir da manipueira em reator anaeróbio de leito fluidificado. 2012. $106 \mathrm{f}$. Dissertação (Mestrado em Recursos Hídricos e Saneamento) - Universidade Federal de Alagoas, Maceió, 2012.

AMORIM, N. C. S. et al. Biohydrogen production from cassava wastewater in an anaerobic fluidized bed reactor. Brazilian Journal of Chemical Engineering, vol. 31 (3), 603-612 (2014).

APHA. Standard Methods for the examination for water and wastewater. 20th Ed. Washington, DC, American Public Health Association/American Water Works Association/Water Environmental Federation (1998).

BARROS, et al. Biohydrogen production in anaerobic fluidized bed reactors: Effect of support material and hydaulic retention time. International Journal of Hydrogen Energy, 35: p. 3379-3388, 2010.

BUITRÓN, G. et al. Hydrogen and methane production via a two-stage processes (H2-SBR + CH4-UASB) using tequila vinasses. International Journal of Hydrogen Energy, http://dx.doi. org/10.1016/j.ijhydene.2014.04.139, 2014.

Production process. Appl. Microbiol. Biotechnol., vol. 58, 224228 (2002).

CARDOSO, P. H. G. Produção de hidrogênio a partir da manipueira em reator anaeróbio de leito fluidificado: Efeito do $\mathrm{pH}$. 2013. Dissertação (Mestrado em Recursos Hídricos e Saneamento) - Universidade Federal de Alagoas, Maceió, 2013.

CAPPELLETTI, B. M. et al. Fermentative production of hydrogen from cassava processing wastewater by Clostridium acetobutylicum. Renew Energy 2011;36(12):3367-72.

CHEN, CC; LIN, CY; LIN, MC. Acid-base enrichment enhances anaerobic hydrogen

COLIN, X. et al. Anaerobic treatment of cassava starch extraction wastewater using a horizontal flow filter with bamboo as support. Science Direct. Bioresource Technology. v. 98, p. 16021607, 2007.
DE GIOANNIS, G. et al. A review of dark fermentative hydrogen production from biodegradable municipal waste fractions. Waste Manag 2013;33:1345-61.

DEMIREL, B. et al. Production of methane and hydrogen from biomass through conventional and high-rate anaerobic digestion processes. Crit Rev Env Sci Tec 2010;40:116-46.

DUBOIS, S. M. et al. Colorimetric Methods for determination of sugar and related substance. Analytical Chemistry, v. 228, p. 13-21. 1956.

GUO, X. M. et al. Hydrogen production from agricultural waste by dark fermentation: A review. International journal of hydrogen energy 2010; 35:10660-10673.

HERNÁNDEZ, M. A., SUSA, M.R., ANDRES, Y. Use of coffee mucilage as a new substrate for hydrogen production in anaerobic co-digestion with swine manure. Bioresource Technology 2014;168:112-118

HUBBARD RK, LOWRANCE RR. Dairy cattle manure management. In: Agricultural utilization of municipal, animal and industrial wastes. USDA, Agric. Res. Service, Conservation Res. Rep44; 1998. p. 91-100 LI, Y. et al.

The Effect of pH on Continuous Biohydrogen Production from Swine Wastewater Supplemented with Glucose. Appl Biochem Biotechnol. 162:1286-1296, 2010.

von SPERLING, M. Introdução à qualidade das águas e ao tratamento de esgotos - Marcos von Sperling. 4 ed. Belo Horizonte: Editora UFMG, 2014.

MAINTINGUER, S. I. et al. Fermentative hydrogen production by microbial consortium. International Journal of Hydrogen Energy, 33(16), 4309-4317 (2008).

MARONE, A. et al. Optimization of substrate composition for biohydrogen production from buffalo slurry co-fermented with cheese whey and crude glycerol, using microbial mixed culture. Int J Hydrogen Energy 2015;40:209-218.

ROSA, P. R. F. et al. The effects of seed sludge and hydraulic retention time on the production of hydrogen from a cassava processing wastewater and glucose mixture in an anaerobic fluidized bed reactor. Int J Hydrogen Energy 2014;39:13318-13127.

REIS, C. M. Efeito da velocidade ascencional na produção de hidrogênio em reator anaeróbio de leito fluidificado. 2010. $97 \mathrm{f}$. Dissertação (Mestrado em Engenharia Hidráulica e Saneamento) - Universidade de São Paulo, São Carlos, 2010.

RIAÑO, B.; MOLINUEVO, B.; GARCÍA-GONZÁLEZ, M. C. Potential for methane production from anaerobic co-digestion of swine manure with winery wastewater. Bioresource technology, 102.5: 4131-4136, 2011.

SANTOS, E.C.L. Produção biológica de hidrogênio utilizando resíduo de suinocultura suplementado com sacarose. 2014. Dissertação (Mestrado em Recursos Hdricos e Saneamento) - Universidade Federal de Alagoas.

WANG, W. et al. Enhanced fermentative hydrogen production from cassava stillage by co-digestion: the effects of different co-substrates. Int J Hydrogen Energy 2013;38(17):6980-8.

ZHANG, Z. P. et al. Biohydrogen production in a granular activated carbon anaerobic fluidized bed reactor. Int. J. Hydrogen Energy, v. 32, p. 185-191, 2007. 